\title{
Optimal control applied to an irrigation planning problem: a real case study in Portugal
}

\author{
Sofia O. Lopes, Rui M.S. Pereira* and \\ Paulo A. Pereira \\ Department of Mathematics and Applications and CMAT, \\ University of Minho, \\ Braga, Portugal \\ Email: sofialopes@math.uminho.pt \\ Email: rmp@math.uminho.pt \\ Email: ppereira@math.uminho.pt \\ *Corresponding author
}

\author{
Amélia C. Caldeira \\ SYSTEC/ISR-Porto and LEMA, \\ Instituto Politecnico do Porto, \\ Porto, Portugal \\ Email: acd@isep.ipp.pt
}

\section{Victor Francisco Fonte}

Department of Informatics and HASLAB,

University of Minho,

Braga, Portugal

Email: vff@di.uminho.pt

\begin{abstract}
In this paper, a daily plan model to the irrigation of a crop field using optimal control was developed. This daily plan model have in consideration: weather data (temperatures, rainfall, wind speed), the type of crop, the location, humidity in the soil at the initial time, the type of soil and the type of irrigation. The aim is to minimise the water used in the irrigation systems ensuring that the field crop is kept in a good state of preservation. MATLAB was used to develop our mathematical model and obtain its output. Its results were compared with experimental ones obtained from a real farm field of grass in Portugal. This comparison not only allowed us to validate our model, but also allowed us to conclude that, using optimal control considerable savings in water resources, while keeping the crop safe are obtained. Some real test cases were simulated and the comparison between the optimised water to be used by the irrigation system (calculated by software) and the real amount of water used in irrigation site (on-off control system for irrigation) produced water savings above $10 \%$.
\end{abstract}

Keywords: optimal control; irrigation systems; real data; water resources; Portugal. 
Reference to this paper should be made as follows: Lopes, S.O., Pereira, R.M.S., Pereira, P.A., Caldeira, A.C. and Fonte, V.F. (2019) 'Optimal control applied to an irrigation planning problem: a real case study in Portugal', Int. J. Hydrology Science and Technology, Vol. 9, No. 2, pp.173-188.

Biographical notes: Sofia O. Lopes obtained her $\mathrm{PhD}$ and a $\mathrm{ScD}$ degree in Mathematics at the Universidade do Minho. Since 2003 she has been on the academic staff of Departamento de Matemáticae Aplicações at the Universidade do Minho. Her research interests are in the areas of optimal control and optimisation.

Rui M.S. Pereira received his $\mathrm{PhD}$ in Mathematical Sciences at the University of Manchester UK and has publications in the areas such as mathematics, physics, engineering and education. $\mathrm{He}$ is an Assistant Professor of Mathematics, at the University of Minho in Portugal.

Paulo A. Pereira received his PhD in Mathematical Sciences at the University of Minho and has several publications in the area of mathematics, physics, engineering and education. He is a Lecturer of Mathematics at the University of Minho in Portugal.

Amélia C. Caldeira obtained her $\mathrm{PhD}$ in Applied Mathematics at the Universidade do Porto. Since 1997 she has been on the academic staff of Departamento de Matemática at the Instituto Superior de Engenharia do Porto do Instituto Politécnico do Porto. Her research interests are in the areas of model predictive control, optimisation and mathematics and engineering education.

Victor Francisco Fonte obtained his $\mathrm{PhD}$ and MSc degrees in Informatics at the Universidade do Minho, in Portugal. He is a Lecturer at the Informatics Department at the same institution since 1993, a research member of INESC TEC since 2012, and he currently holds an Adjunct Professor position at the University of United Nations EGOV Operating Unit. His main research interests are distributed systems and cyber-security.

\section{Introduction}

According to Stocker et al. (2013), climate change is a reality and it will severely affect our lives. The temperature in certain parts of the globe increased as much as 2.5 degrees in the last century. This phenomenon has continuing and accelerating growth. On the other hand, in Iberian Peninsula, the rainfall is also expected to drop and, consequently, water resource is already an issue.

The amount of freshwater available in our planet is only $2.5 \%$ of all the existing water. From this small slice, $70 \%$ is used in agriculture, where, as it is know, the wasted water is significant, see for example Frenken et al. (2012). In this context, it is crucial save water, especially in agriculture, see Haie et al. $(2012,2011)$ and Dalezios et al. (2017).

The importance of the study of irrigation systems can be seen in Valipour et al. (2015). Most irrigation systems for sale in the market are based on the on-off control with no prediction techniques; the system triggers the irrigation cycle when a minimum critical 
value of soil moisture is detected and suspends it when a defined maximum is reached (sometimes close to saturation). The excess of water in the soil, that is frequently a result of these types of systems, is responsible for a significant water waste. We developed an irrigation system in which soil moisture does not present abrupt variations in order to achieve effectively minor water expenditure. A careful planning of water needs, as opposed to unplanned strategies of water consumption, e.g., on-off irrigation systems, promotes significant water savings. This is achieved by implementing a smart strategy which uses data from the past and a prediction of future events, using techniques of optimal control. Optimal control theory emerged as a field of research in the 1950s in response to problems concerning the aerospace exploration of the solar system. Optimal control problems involve the minimisation of a cost function which depends on a state and control related through differential equations and other constraints involving the control and/or the state. The fact that one can specify a set control constraints combined with the possibility of dealing with general cost functions enlarge the applicability of optimal control problems to a wide range of control engineering problems, see Martin et al. (1993), Lenhart et al. (2007), SubChan et al. (2009), Van Straten et al. (2010), Lee et al. (2014), Asprion et al. (2001) and Xiang et al. (2015).

Other works were designed to take advantage of storing rainwater to save water consumption. See Zahraei et al. (2017) and Fawal et al. (1998).

Our software uses the weather data to obtain the best irrigation plan for 10 days ahead. To do so, an existing yearly model, Lopes et al. (2016) was adapted to a daily model. In this work, we used weather for 10 consecutive days from the ISEP (http://www.meteo.isep.ipp.pt) website, that allows us to determine the rainfall and the evapotranspiration which are essential parcels of our dynamics. The evapotranspiration is calculated using a simplified version of Pennman-Monteithm (Allen et al., 1998; Walter et al. 2002). Howerever, other formulas to determine evapotranspiration are being proposed, see Goodarzi et al. (2017). The results are in agreement with the expectations, that is, in rainfall days the irrigation system is inactive and, in the drought days the irrigation systems have to be activated.

In order to validate our new model, our results were compared against results from irrigation system of a real farm field from Instituto Superior de Engenharia do Porto (ISEP), in Portugal, that uses on-off control irrigation system. Our results are good and promising as one can read in Section 3. Further tests need to be done for industrial validation.

The paper is divided in four sections: in Section 2 the model for an irrigation system based on the optimal control theory is presented, where the dynamic is given by the hydrological balance equation; in Section 3, the discrete-time model for the irrigation problem is presented. Numerical results are analysed and compared with real situations; finally, in Section 4 conclusions and future work are shown.

\section{The irrigation problem}

The irrigation problem consists in optimising the water used in the irrigation of farm fields via a planning strategy by means of the optimal control with inequality constraints, where the trajectory $(x)$ is the water in the soil and the control $(u)$ is the flow of water introduced in the soil via irrigation system. The formulation is: 
$\min \int_{0}^{T} u(t) d t$

subject to :

$$
\begin{array}{ll}
\dot{x}(t) & =f(t, x(t), u(t)) \text { a.e. } t \in[0, T] \\
x(t) \geq x_{\min } & \forall \in[0, T] \\
u(t) \in[0, M] & \text { a.e. } \\
x(0)=x_{0} &
\end{array}
$$

where $f$ is the hydrologic balance function, $x_{\min }$ is the hydrological need of the crop [according to Raposo (1996)], $x_{0}$ is an initial state, $T$ is a given time and $M$ is the maximum flow of water that comes from tap.

\subsection{The dynamic equation}

As seen before the dynamic equation is given by:

$$
\dot{x}(t)=f(t, x(t), u(t)) \text { a.e. } t \in[0, T]
$$

where the dynamic function, that represents the hydrologic balance, is given by $f(t, x, u)=u+r f a l l(t)-\operatorname{evtp}(t)-\operatorname{loss}(t, x)$, where $\operatorname{rfall}(t)$ is the daily precipitation read from the website ISEP (http://www.meteo.isep.ipp.pt), evtp(t) is the estimated evapotranspiration for the type of $\operatorname{crop}, \operatorname{loss}(t, x)$ represents the losses due runoff and deep percolation.

\subsection{Rainfall - rfall $(t)$}

As said before the rainfall is defined via $r f a l l(t)$. It has the daily precipitation until a maximum of ten days, read from the website ISEP (http://www.meteo.isep.ipp.pt).

\subsection{Evapotranspiration - evtp $(t)$}

The evapotranspiration is composed by the evaporation and the plant's transpiration. For a given crop, we may say, that:

$$
\operatorname{evtp}(t)=K_{c} e v t p_{0}(t)
$$

where $K_{c}$ is a specific value according to the crop, see Raposo (1996) and evtp $(t)$ is the reference evapotranspiration, that was estimated using Pennman-Monteith equation (Allen et al., 1998; Walter et al., 2002):

$$
e v t p_{0}=\frac{0.408 \Delta\left(R_{n}-G\right)+\gamma \frac{900}{T+273} U_{2}\left(e_{a}-e_{d}\right)}{\Delta+\gamma\left(1+0.34 U_{2}\right)}
$$

where, $R_{n}$ is the net radiation at the crop surface $\left[M J m^{-2} d a y^{-1}\right], G$ is the soil heat flux density $\left[\mathrm{MJm}^{-2} d a y^{-1}\right], e_{a}-e_{d}$ is saturation vapour pressure deficit $[\mathrm{KPa}], U_{2}$ is wind speed at $2 \mathrm{~m}$ height $\left[\mathrm{ms}^{-1}\right], T$ is mean air temperature at $2 \mathrm{~m}$ height $\left[{ }^{\circ} \mathrm{C}\right], \Delta$ is the slope vapour pressure curve $\left[\mathrm{kPa}^{\circ} \mathrm{C}^{-1}\right]$ and $\gamma$ is the psychrometric constant $\left[\mathrm{kPa}^{\circ} \mathrm{C}^{-1}\right]$. 
However, since not all data is available, an approximation to this formula was used. A good estimation for $e v t p_{0}$ is obtained using the following inputs: date, location, altitude, maximum and minimum temperature and wind speed at $2 \mathrm{~m}$ height. See for example in Pereira (2004).

\section{$2.4 \operatorname{Losses}-\operatorname{loss}(t, x)$}

The losses due deep percolation were modelled as follows:

$$
\operatorname{loss}(t, x)=\left\{\begin{array}{cc}
k(t) x, & x \leq x_{F C} \\
x-x_{F C}+k(t) x, & x>x_{F C}
\end{array}\right.
$$

where $x_{F C}$ represents the amount of water retained in the soil after the the soil was drained. It depends on the type of soil. If $x<x_{F C}$ the losses are explained by Horton's equations, see Lopes et al. (2016). On the other hand, if $x>x_{F C}$ (the water is no longer absorbed by the soil), the losses are given by the sum of the excess of water in the soil with the losses that are explained by Horton's equation, see Horton $(1940,1945)$. The determination of $k(t)$ was done by comparing the trajectory obtained from our model and the real trajectory. Note that $k(t)$ is such that minimises the sum of the quadratic errors between the two mentioned trajectories.

\section{Discrete-time model for the irrigation problem}

In this section, we intend to obtain the numerical solution to our problem using sequence of finite dimensional nonlinear programming problems. From now on, the following corresponding discrete-time model:

$$
\begin{array}{ll}
\min \sum_{i=0}^{N-1} u_{i} & \\
\text { s.t. : } x_{i+1}=x_{i}+\theta F\left(t_{i}, x_{i}, u_{i}\right), & i=0, \ldots, N-1 \\
x_{i} \geq x_{\min }, & i=0, \ldots, N \\
u_{i} \in[0, M], & i=0, \ldots, N-1 \\
x_{0}=a, &
\end{array}
$$

where $x_{i}$ is the trajectory and $u_{i}$ is the control at time step $i, F$ is balance water function, $x_{\min }$ is the hydrological need of the crop, $a$ is an initial state, $\theta$ is the time step discretisation and $N$ is the number of days for which our model was applied. The dynamic equation implements the water balance in the soil:

$$
F\left(t_{i}, x_{i}, u_{i}\right)=u_{i}+\operatorname{rainfall}\left(t_{i}\right)-\operatorname{evapot}\left(t_{i}\right)-\operatorname{losses}\left(t_{i}, x_{i}\right),
$$

where the evapot is the evaporation from the soil and the transpiration of the crop and the losses mean the losses of water due to the runoff and deep infiltration. The rainfall, evapotranspiration and losses models were described in previous sections. In order to solve the optimisation problem, the MATLAB function 'fmincon' was used. The algorithm used was active set (the default option). In order to test our software, four test cases were considered. Note that these cases use real data from a crop field in ISEP from 
Porto, Portugal and the chosen culture was grass. So, the following four parameters of our model are defined as $x_{\min }=18.72 \mathrm{~mm}, \mathrm{M}=10 \mathrm{~m}^{3} /$ day, $K_{c}=0.95, x_{F C}=46.8 \mathrm{~mm}$.

\subsection{Results and qualitative validation of the model}

In the next four examples, we are able to verify that our results correspond to reality. In two of these examples there is enough rainfall for the crop to survive and in the last two examples, there is a situation of drought and the irrigation system has to be activated. These examples correspond to a period of ten consecutive days in a field in ISEP.

Figure 1 Results for Case 1 (see online version for colours)

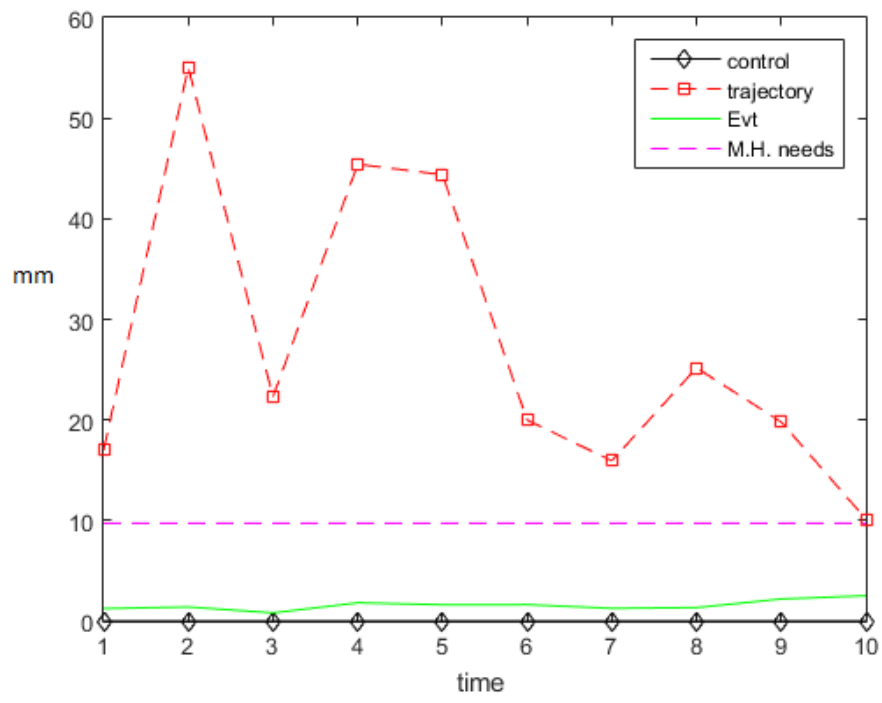

\subsubsection{Case 1}

In the first case there was heavy rainfall. It corresponds to the period between 1st May and 10th May of 2015. The precipitation in this period was as follows:

$50.29,3.81,33.02,30.73,1.27,0.76,15.53,0.76,0,0](\mathrm{mm})$.

As the rainfall is abundant, the humidity in the soil is always above the level where the crop enters is distress. There is no need for irrigation. When rain is abundant, the second branch of the losses function (5) is used. See Figure 1.

\subsubsection{Case 2}

The second case there was light rainfall. It corresponds to the period between 14th October and 24th October of 2015. The precipitation in this period was as follows:

$$
[0,0,0,0.76,12.95,0.25,0,0,0,0](\mathrm{mm})
$$

The results obtained are in Figure 2. 
Figure 2 Results for Case 2 (see online version for colours)

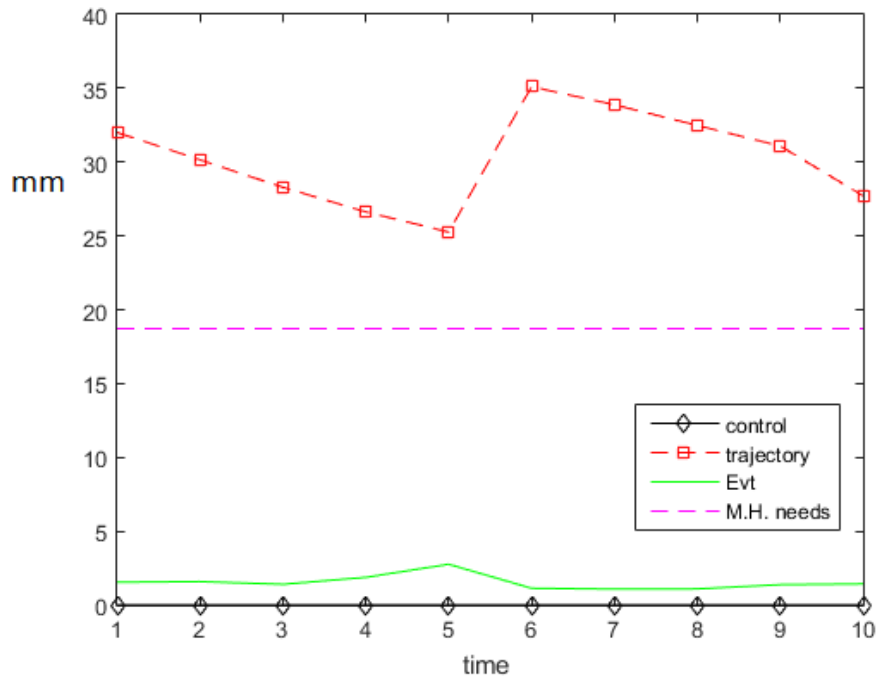

There is no need for irrigation, since the humidity in the soil is always above the level where the crop enters is distress. Since rain is not abundant, only the first branch of the losses function (5) is used.

\subsubsection{Case 3}

The third case there was drought without precipitation. It corresponds to the period between 1st August and 10th August of 2015.

Figure 3 Results for Case 3 (see online version for colours)

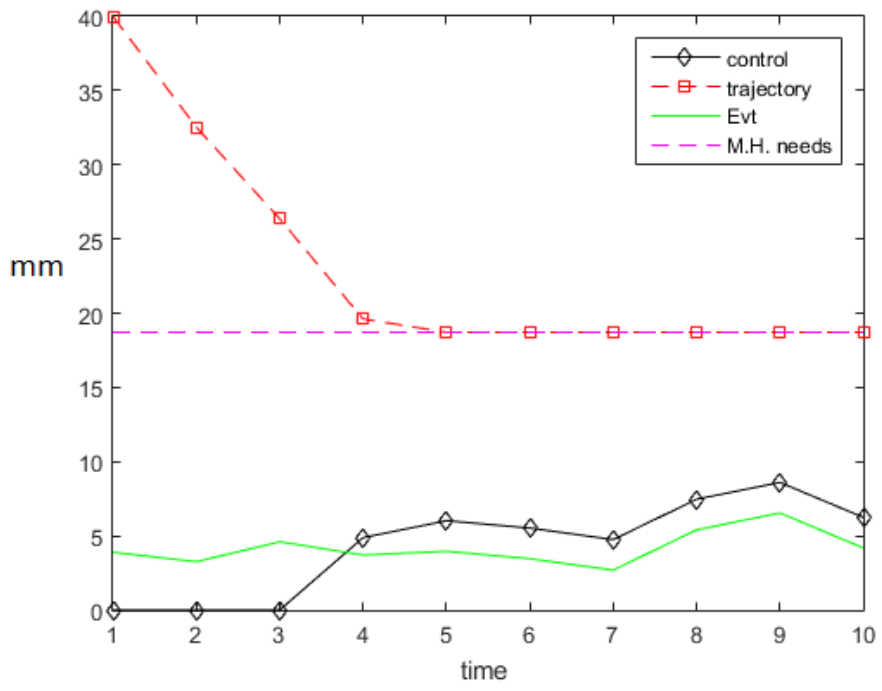

The results obtained can be seen in Figure 3. 
It does not rain at all in the period considered in this case. The humidity in the soil drops very fast and the control (irrigation) has to be activated after 2 days. As one can see in Figure 3, once the irrigation is activated, it remains until the end of the period in study, guaranteeing just enough water for the crop to survive.

Figure 4 Results for Case 4 (see online version for colours)

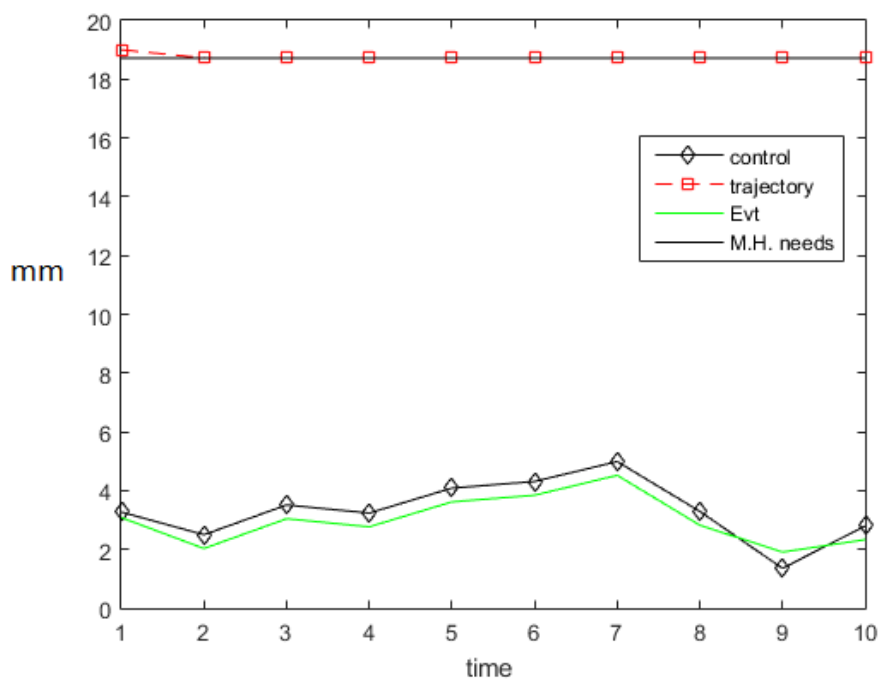

\subsubsection{Case 4}

The fourth case there was drought. It corresponds to the period between 1st September and 10th September of 2015. The rain is very scarce, the precipitation in this period was as follows:

$$
[0,0,0,0,0,0,0,0,1.02,0](\mathrm{mm}) .
$$

The results obtained can be seen in Figure 4.

The humidity in the soil was already at its minimum level (for the crop to survive) and therefore the control (irrigation) has to be activated for the whole period. It provides just enough water for the crop to survive. Note that in day 9, evapotranspiration value is slightly above irrigation value, since there was light rainfall.

From these four examples, it is possible to say that the model is qualitatively good.

\subsection{Comparison between numeric solution for humidity in the soil and real data for humidity in the soil}

The instruments used in ISEP to measure the soil tension provide us the output in pressure units. To compare this results with ours, one has to convert our results from $\mathrm{mm}$ to percentage of the volume of the soil occupied with water and, finally from the last one to tension of water in the soil $(\mathrm{kPa}-$ pressure $)$. 
Figure 5 Tension of water in the soil versus water in the soil for different types of soil

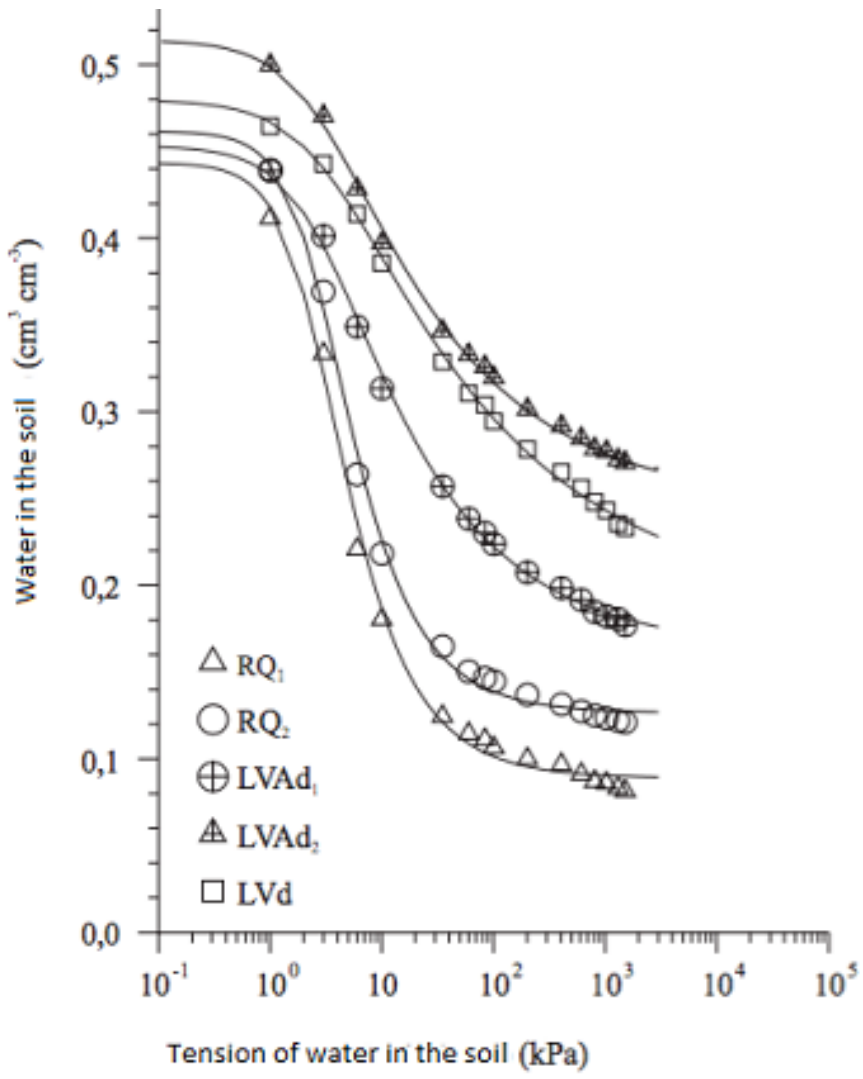

Source: da Silva et al. (2006)

To perform the conversion of units properly, the characteristics of the soil should be studied in a laboratory. We do not have the possibility to do that at this moment. In Figure 5 from da Silva et al. (2006) we may see the relationship between tension of the water in the soil $(\mathrm{kPa})$ and the correspondent percentage of the volume of the soil occupied with water. The curve LVDA1 da Silva et al. (2006) ( to $32.8 \%$ clay, $14.2 \%$ of sand, $52.70 \%$ of thin sand, $0.3 \%$ silt, with the soil density of $1,317 \mathrm{~kg} / \mathrm{m}^{3}$ ) was considered. Taking a number of points from that curve, we defined a polynomial function that best fits the curve (using a least squared error approach). Note that LDVA1 is the intermediate curve. It provided fairly good results and so, it was assumed that it probably represents an approximation to the type of soil in ISEP.

The conversion from $\mathrm{mm}$ to percentage of the volume of the soil occupied with water was done taking into account:

$$
x_{i}=\left(\theta_{i}-\theta_{w p}\right) * p p * z r * 1,000
$$

measured in mm, where $\theta_{i}$ is percentage of the volume of the soil occupied with water, $\theta_{w p}$ is percentage of the volume of the soil occupied with water when the soil is dry, $z r=0.75 \mathrm{~m}$ is the height of the plant's root and $p p=40 \%$ is percentage of the volume of 
the soil occupied with water bellow which the plant is suffering, see Gonçalves et al. (1997) and Pereira (1995).

Figure 6 Results (a) for Case 1 and (b) for Case 2 (lower panel) (see online version for colours)

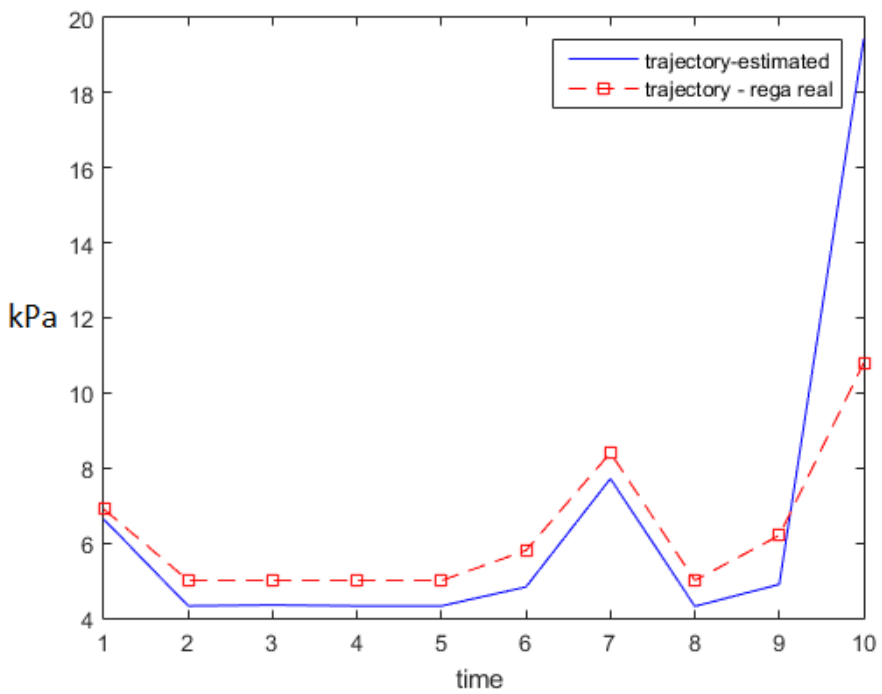

(a)

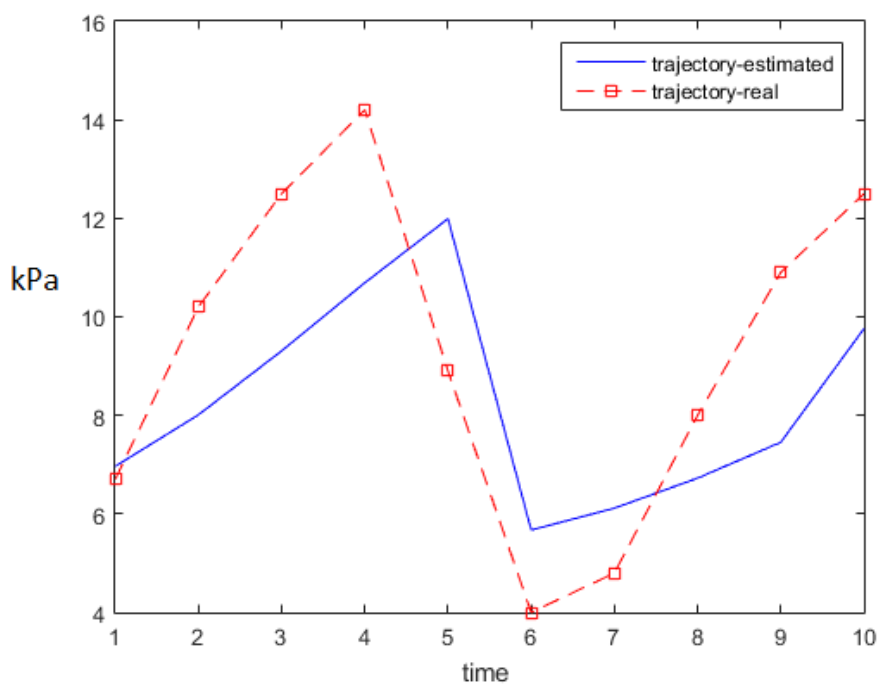

(b)

Our next step is to validate the model taking into account measures of water in the soil in the real crop field, measured in (kpa). The numerical results are for the same four cases as before (all inputs are equal). Case 1 and 2 did not need irrigation. Real humidity in the soil and, the one that our software provides, will be compared. In Case 3 and 4, since there is irrigation, it will be compared our solution (in terms of humidity in the soil), with the solution obtained using our model having the real irrigation as input. These two 
results are also compared with the real humidity in the soil measured in site with appropriate instruments. Note that a measurement of humidity in the soil below $5 \mathrm{kPa}$, means the soil is close to saturation, if this value is above $20 \mathrm{kPa}$ the soil is dry. Since soil moisture tension is a measure of suction, it should be negative. The minus sign was dropped for matters of convenience.

\subsubsection{Case 1 and Case 2}

Recall that there is no irrigation for both cases. This was verified both as output of our software and in the real crop field. The results obtained can be seen in Figure 6.

Figure 7 Results for Case 3 in terms of (a) trajectory and (b) control (see online version for colours)

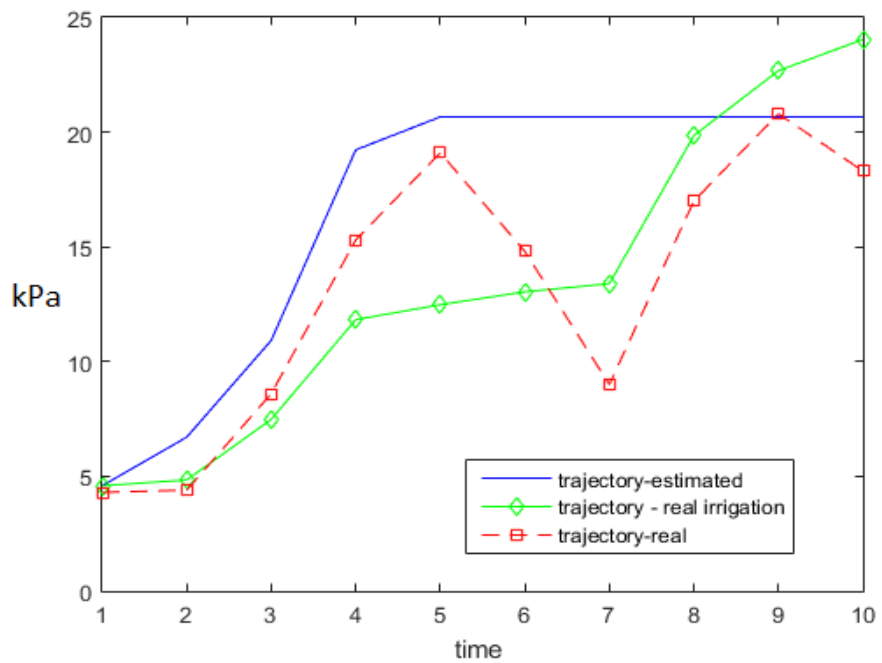

(a)

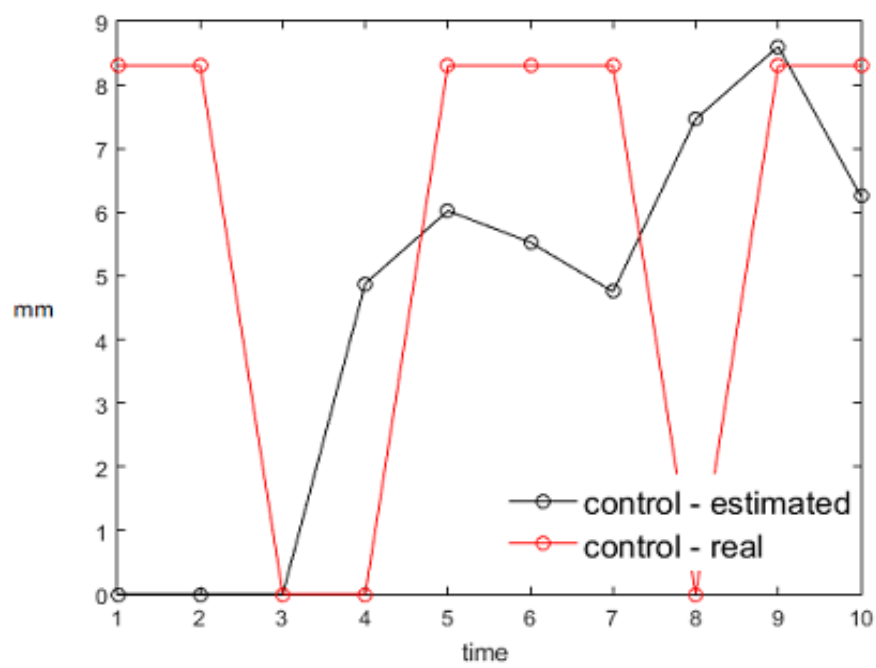

(b) 
As one can see, the solution obtained for the humidity in the soil using our model is similar to the real one.

Figure 8 Results for Case 4 in terms of (a) trajectory and (b) control (see online version for colours)

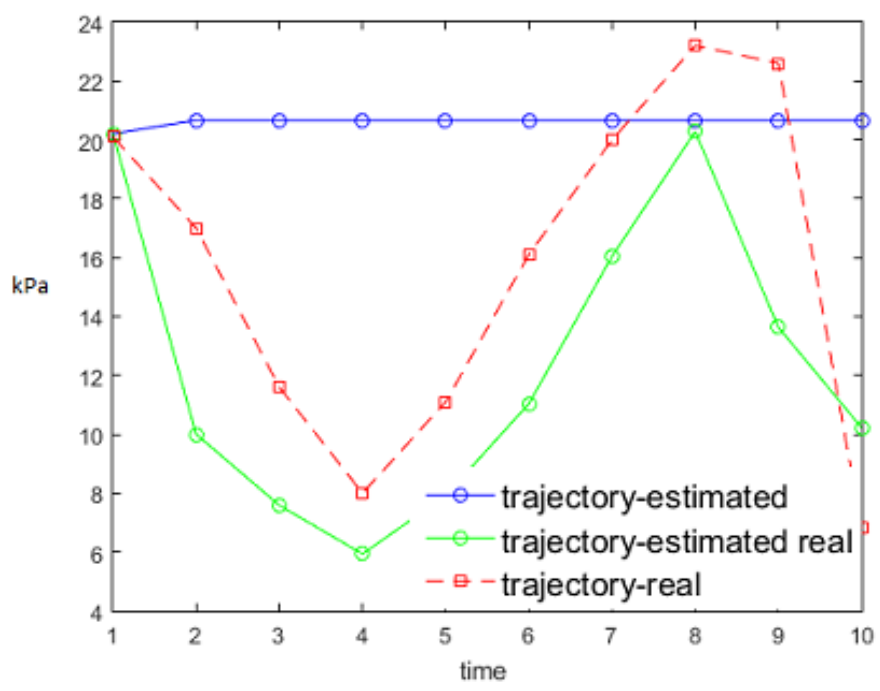

(a)

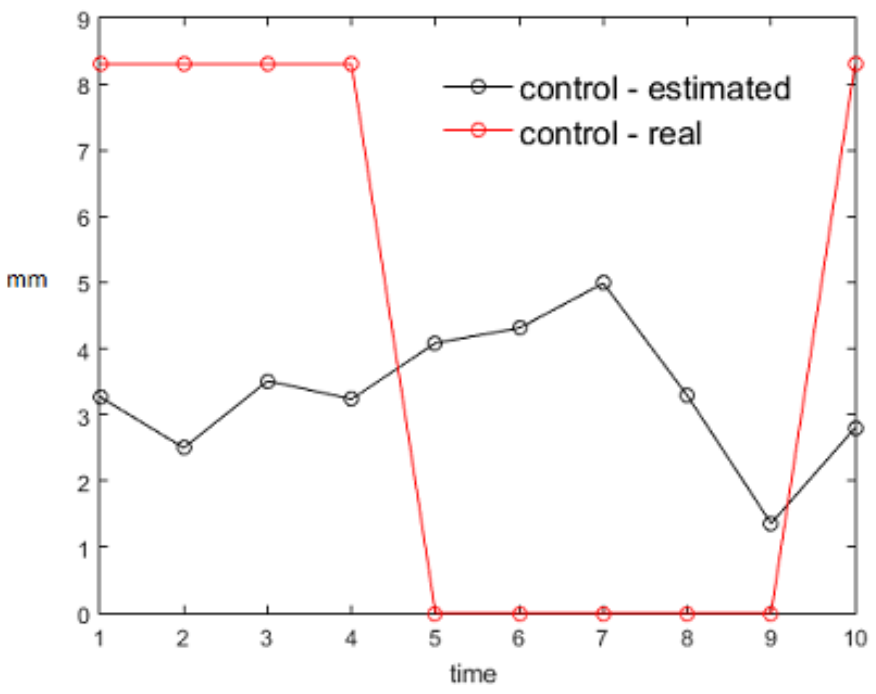

(b)

\subsubsection{Case 3}

In this example, it can be seen that initially the soil is close to saturation. Then, due to the lack of rainfall, the soil dries up very fast. Our optimal solution (curve in blue) guarantees that the plant survives, spending the minimum amount of water. When, our software is 
used, with the real amount of water used in irrigation as input (curve in green) the behaviour of the computed humidity in the soil is close to the real one (curve in red). This qualitatively validates the model developed. Another issue is the comparison between the optimised water used in the irrigation system using our simulation (black curve) and the real amount of water used in irrigation by ISEP (note they use an on-off control system for irrigation). One can estimate that we may achieve a $16.8 \%$ of water savings. The results obtained can be seen in Figure 7.

\subsubsection{Case 4}

In this example, it can be seen that initially the soil is close to the minimum needs of the crop. Then, due to the lack of rainfall, the irrigation starts right away. Our optimal solution (curve in blue) guarantees that the plant survives, spending the minimum amount of water.

As expected, the curve in blue is almost horizontal, which correspond to the hydric need of the plant. Using our software with the real amount of water used in irrigation as input (curve in green) the behaviour of the computed humidity in the soil is very close to the real one (curve in red). This validates qualitatively the model that developed.

Another issue, is the comparison between the optimised water used in the irrigation system calculated by our (black curve) and the real amount of water used in irrigation by ISEP (note they use an on-off control system for irrigation). One can estimate that we may achieve $11.1 \%$ of water savings. The results obtained can be seen in Figure 8.

\section{Conclusions}

According to Stocker et al. (2013), climate change is a reality and it will severely affect our lives. The temperature in certain parts of the globe increased as much as 2.5 degrees in the last century. This phenomenon has continuing and accelerating growth. On the other hand, in Iberian Peninsula, the rainfall is also expected to drop and, consequently, water resource is already an issue.

A careful planning of water needs, as opposed to unplanned strategies of water consumption, e.g., on-off irrigation systems, promotes significant water savings. This is achieved by implementing a smart strategy which uses data from the past and a prediction of future events, using techniques of optimal control. The implemented model, using such techniques, is easily adapted to the different hydric needs of the crop. Another issue is related with the growth of the crop. The plant's hydric needs are vary with time and the implemented model is able to cope with this, with minor changes.

The fact that we are planning the irrigation (using optimal control tools), avoid abrupt variations of the water in the soil and consequently, reduce the water losses. On the other hand, the crop keeps healthy. Using this approach, it is guaranteed, that a minimum value of irrigation is obtained at each time step, assuming that the weather forecast data is not very far from reality. It is our intention to implement a re-plan strategy, in order to avoid major errors, when the weather forecast fails.

A software was developed such that, when fed by the weather data for ten days head, obtains the best irrigation plan for that time period. To do so, we adapted the existing model (Lopes et al., 2016). In order to solve the optimisation problem, we used the MATLAB function 'fmincon', where the algorithm used was active set (the default 
option). Note that in the previous mentioned model, monthly rainfall was defined as the average of the previous ten years, the evapotranspiration has a specific value for the crop and for a certain location. In this work, the previous model was adapted, to study a daily water planning. The weather variables (prediction for the ten days head) were taken from the website ISEP (http://www.meteo.isep.ipp.pt). The evapotranspiration present in the dynamics of the problem was computed using a simplified version of Pennman-Monteith (Walter et al., 2002). The obtained solutions are good.

Moreover, two types of situations were studied. In first situation, there was significant rainfall and the irrigation system, as expected was not activated. This was also true in site. In this case, it was proved that the estimated amount of water in the soil and the actual amount of water in the soil measured by ISEP, were very close. In the second situation, there was no rainfall. An optimal solution was obtained, where the irrigation estimated by our software guaranteed that the water in the soil goes to the minimum amount of water that preserves the crop and keeps that way. By doing so, savings of water are guaranteed. In order to validate the model it was compared the real humidity in the soil, versus the humidity in the soil using our simulation having as input the real amount of water used by the irrigation system of ISEP. Once again, one can see that the numerical results are in agreement with the real ones.

Another issue studied here was the comparison between our optimal solution and the real amount of water used in the farm field. In one of the considered test cases, it is possible to save as much as $16 \%$ of water. Other in site test are needed, but, we believe that, the tool developed, when the proper hardware is ready to install in a farm field, can be very useful to the farmers, specially in regions of the world where water is scarce.

It is expected that the model would work for any type of cultures (irrigated everyday or otherwise). The constraint is that enough data to run the developed software is available.

\section{Acknowledgements}

This work was partially supported by UID/MAT/00013/2013, PTDC/EEIAUT/2933/2014, NORTE Regional Operational Program through Project NORTE-45-2015-02 STRIDE - Smart Cyberphysical, Mathematical, Computational and Power Engineering Research for Disruptive Innovation in Production, Mobility, Health and Ocean Systems and Technologies, as well as projects POCI-01-0145-FEDER-006933 - SYSTEC-Research Center for Systems and Technologies - Institute of Systems and Robotics, Universidade do Porto, are gratefully acknowledged. We also thanks to José Barros de Oliveira and ISEP to let us use the data from ISEP.

\section{References}

Allen, R., Pereira, L., Raes, B. and Smith, M. (1998) Crop Evapotranspiration (Guidelines for Computing Crop Water Requirements)', FAO Irrigation and Drainage Paper.

Asprion, J., Chinellato, O. and Guzzella, L. (2001) 'Optimal control of diesel engines: numerical methods, applications, and experimental validation', Mathematical Problems in Engineering, p.21 [online] http://www.dx.doi.org/10.1155/2014/286538. 
da Silva, E., Lima, J., Azevedo, J. and Rodrigues, M. (2006) 'Valores de tensão na determinação da curva de retenção da água de solos do Cerrado', Pesquisa Agropecuária Brasileira, Vol. 41, No. 3, pp.323-330.

Dalezios, R., Angelakis, A., Eslamian, S. (2017) 'Water scarcity management: Part 1: methodological framework', International Journal of Hydrology Science and Technology, in press.

Fawal, H, Georges, D., Bornard, G. (1988) 'Optimal control of complex irrigation systems via decomposition-coordination and the use of augmented Lagrangian', Systems, Man, and Cybernetics - IEEE International Conference, pp.3874-3879.

Frenken, K. and Gillet, V. (2012) Irrigation Water Requirement and Water Withdrawal by Country, AQUASTAT Report, Food and Agriculture Organization of the United Nation, Rome [online] http://www.fao.org/3/a-bc824e.pdf.

Gonçalves, M., Pereira, L. and Leij, F. (1997) 'Pedo-transfer functions for estimating unsaturated hydraulic properties of Portuguese soils', European Journal of Soil Science, September, Vol. 48, No. 3, pp.387-400.

Goodarzi, M. and Eslamian, S. (2017) 'Performance evaluation of linear and nonlinear models for the estimation of reference evapotranspiration', International Journal of Hydrology Science and Technology, in press.

Haie, N., Machado, G., Pereira, R.M.S. and Keller, A. (2011) 'Effective efficiency in water resources management using efficiency elasticity index', Water and Environment Journal, Vol. 25, No. 4, pp.532-539.

Haie, N., Pereira, R.M.S., Machado, G. and Keller, A. (2012) 'Analysis of effective efficiency in decision making for irrigation interventions’, Water Resources, Vol. 39, No. 6, pp.700-707.

Horton, R.E. (1940) 'An approach toward a physical interpretation of infiltration-capacity', Soil Science Society of America Proceedings, Vol. 5, pp.399-417 [online] http://www.hydrology.agu.org/wp-content/uploads/sites/19/2016/06/Horton1940.pdf.

Horton, R.E. (1945) 'Erosional development of streams and their drainage basins; hydrophysical approach to quantitative morphology', Geological Society of America Bulletin, Vol. 56, No. 3 , pp.275-370.

ISEP, Meteorologia no Instituto Superior de Engenharia do Porto [online] http://www.meteo.isep.ipp.pt (accessed June 2016)

Lee, H.W.J, Cai, X.Q. and Teo, K.L. (2014) 'An optimal control approach to manpower planning problem', Mathematical Problems in Engineering, Vol. 7, No. 2, pp.155-175 [online] http://www.dx.doi.org/10.1155/S1024123X01001594.

Lenhart, S. and Workman, J. (2007) Optimal Control Applied to Biological Models, p.274, 7 May, Chapman and Hall/CRC Textbook, 42 B/W Illustrations, CAT\# C6404, Chapman \& Hall/CRC Mathematical and Computational Biology, ISBN: 9781584886402 [online] http://www.crcpress.com/Optimal-Control-Applied-to-Biological-Models/Lenhart-Workman/ $\mathrm{p} /$ book/9781584886402.

Lopes, S., Pereira, R.M.S., Fontes, F., Pinho, M. de R., Gonçalves, M. (2016) 'Optimal control applied to an irrigation planning problem', Mathematical Problems in Engineering, p.10, [online] http://www.dx.doi.org/10.1155/2016/5076879.

Martin, R. and Teo, K. (1993) 'Optimal control of drug administration in cancer chemotherapy', World Scientific, ISBN: 978-981-02-1428-9 [online] http://www.worldscientific.com/ worldscibooks/10.1142/2048

Pereira, L.S. (1995) Proceedings of the 2nd Workshop on Crop-Water-Models held at the occasion of the 15th Congress of the International Commission on Irrigation and Drainage (ICID), at The Hague 1993. Publication date: 1995 [online] http://www.library.wur.nl/WebQuery/ wurpubs/302257.

Pereira, L.S. (2004) Necessidades de água e métodos de rega, Publicaçoes Europa - América.

Raposo, J.R. (1996) A REGA - dos primitivos regadios as modernas técnicas de rega, Fundação Calouste Gulbenkian. 
Stocker, T.F.D., Qin, G-K., Plattner, M., Tignor, S.K., Allen, J., Boschung, A., Nauels, Y., Xia, V.B. and Midgley, P.M. (Eds.) (2013) 'IPCC, 2013: climate change 2013: the physical science basis', Contribution of Working Group I to the Fifth Assessment Report of the Intergovernmental Panel on Climate Change, Cambridge University Press, Cambridge, UK and New York, NY, USA, p.1535, DOI: 10.1017/CBO9781107415324 [online] http://www.climatechange2013.org/report/full-report/.

SubChan, S. and Zbikowski, R. (2009) Computational Optimal Control: Tools and PRACTICE, John Wiley \& Sons, ISBN: 978-0-470-71440-9 [online] http://www.eu.wiley.com/ WileyCDA/WileyTitle/productCd-0470714409.html.

Valipour, M., Sefidkouhi, M. and Eslamian, S. (2015) 'Surface irrigation simulation models: a review', International Journal of Hydrology Science and Technology, Vol. 5, No. 1 pp.51-70.

Van Straten, G., Van Willigenburg, G., Van Henten, E. and Van Ooteghem, E. (2010) Optimal Control of Greenouse Cultivation, CRC Press, Taylor \& Francis Group, ISBN: 9781420059618 [online] http://www.crcpress.com/Optimal-Control-ofGreenhouse-Cultivation/van-Straten-van-Willigenburg-van-Henten-van-Ooteghem/p/book/ 9781420059618.

Walter, I., Allen, R., Elliott, R., Itenfisu, D., Jensen, M., Mecham, B., Howell, T., Snyder, R., Brown, S., Echings, S., Spofford, T., Hattendorf, M., Cuenca, R., Wright, J. and Martini, D. (2016) 'The ASCE standardized reference evapotranspiration equation', Rep. Task Com. on Standardized Reference Evapotranspiration.

Xiang, C., Zhang, D., Zheng, H., Han, L. and Huang, K. (2015) 'A novel nonlinear optimal control approach for the dynamic process of a hybrid electric vehicle equipped with electromechanical transmission', Mathematical Problems in Engineering, Article ID 238264, p.20 [online] http://www.dx.doi.org/10.1155/2015/238264 http://www.hindawi.com/journals/mpe/ 2015/238264/.

Zahraei, A., Saadati, S. and Eslamian, S. (2017) 'Irrigation deficit: farmlands', in Eslamian, S. and Eslamian, F. (Eds.): Management of Drought and Water Scarcity, Handbook of Drought and Water Scarcity, Vol. 3, Ch. 16, pp.343-358, Francis and Taylor, CRC Press, USA. 